\title{
Strategies for the Preservation of Service Levels in the Inventory Management During COVID-19: A Case Study in a Company of Biosafety Products
}

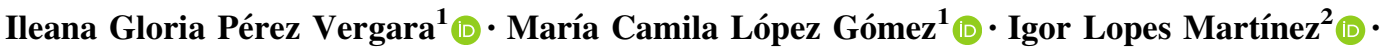 \\ Jesús Vargas Hernández ${ }^{3}$
}

Received: 5 February 2021/Accepted: 8 April 2021/Published online: 5 May 2021

(C) Global Institute of Flexible Systems Management 2021

\begin{abstract}
The current global situation due to the COVID19 pandemic has seriously impacted the ability of supply chains to achieve the availability of essential biosafety products in a timely and reliable manner. The companies producing biosafety products have experienced an unforeseen change in the demand for products, due to the international protocols of health organizations on the use of these types of products to mitigate the spread of the virus. For companies involved in these supply chains, the priority is to maintain adequate service levels in the current scenario, guaranteeing high availability at each link in order to help preserve life. This requires maintaining the articulation and flexibility of the processes in the supply chain, reflected in decision making. Despite the relevance of the problem, studies on multi-product inventory business strategies and their impact on service level and volatile demand during a pandemic are limited. This article shows the experience of a Colombian biosafety products
\end{abstract}

Ileana Gloria Pérez Vergara

ileper@yahoo.com

$\bowtie$ Igor Lopes Martínez

igor.lopesmartinez@gmail.com

María Camila López Gómez

lopezgomezmariacamila@gmail.com

Jesús Vargas Hernández

jvargash@uaemex.mx

1 School of Engineering, Industrial Engineering Program, Universidad de San Buenaventura, Cali, Colombia

2 Department of Industrial Engineering, School of Industrial Engineering, Universidad Tecnologica de la Habana, Habana, Cuba

3 Universidad Autónoma del Estado de México, Estado de México, México company, which, focused on fulfilling its mission, guaranteeing customer and user satisfaction, developed strategies that made its management model of inventories management more flexible. The contribution of this proposal leads to some important knowledge that may be of interest for the management of inventories in biosafety companies that manage multiple products of great demand, volatile behavior and of high importance, which impacts on the containment of the spread of the virus in a global disruption of supply chains. The proposed strategies can be generalized to other types of companies that present similar situations.

Keywords Biosafety · COVID-19 · Flexibility · Inventory $\cdot$ Pandemic management $\cdot$ Service level

\section{Introduction}

A pandemic is defined as an epidemic disease that extends to many countries or that attacks almost all individuals in a locality or region (WHO 2010). Any epidemic outbreak is generally perceived as disturbances that have great uncertainty (Paul et al. 2013, 2014). Due to the dimensions, it reaches in a number of countries, and it generates effects on the supply chain that not only have serious impacts, but also long-lasting ones on its operations.

The COVID-19 pandemic (WHO 2020) has generated interruptions in supply chains, being considered an extraordinary risk for companies in various sectors that have experienced different types of challenges, for some the demands are increasing, and on the other hand, the supply of raw materials, to produce these articles, has been reduced due to the lack of supply (Paul and Chowdhury 2020). 
Due to the regulations and the new lifestyles imposed by the COVID-19 pandemic derived from the recommendation to apply biosecurity ${ }^{1}$ protocols as a measure to mitigate its effects, without a doubt one of the supply chains that has received the greatest impact is that of products of biosecurity; in particular, the modification in the consumption of this type of products has generated changes in the behavior of the demand, which has been reflected both in the type of products and in the quantities to be delivered, generating the Bullwhip effect that spreads through all the links in the chain, creating an environment of instability in the production and distribution systems that significantly decreases its operational and financial performance (Lu et al. 2018; Ponte et al. 2020; Pastore et al. 2020).

Addressing the pressing demand through the development of strategies and the use of unique assets and capabilities, for an essential product, is a social responsibility of companies. In these new conditions, everyone's priority is the preservation of life, making it mandatory for companies to fulfill their social mandate, defining their objectives to maintain or improve their levels of customer service, for which they must continuously analyze scenarios to make decisions, make their processes more flexible and thus adapt quickly to the sudden changes caused by the pandemic (Aldrighetti et al. 2019).

Inventory control is one of the most complex issues in supply chain logistics and management, and the causes associated with the need to maintain inventories of any kind and in any company are random fluctuations in demands and the lead time, both variables in the pandemic were affected (Vidal Holguín 2010; Pérez-Vergara et al. 2013). For small- and medium-sized companies (SMEs), which must compete with multinationals belonging to the same sector, which have greater infrastructure, in terms of processes and financial soundness, this becomes a great challenge. Decisions related to inventory management are especially relevant in a customer service orientation approach, and they are part of a complex system that involves interest groups or stakeholders ${ }^{2}$ parties from different areas of the company and the chain, where each agent has limited information and where cooperation between these agents is key to the performance of the system (Pérez Vergara et al. 2020).

\footnotetext{
${ }^{1}$ Set of measures for the prevention and control of biological risk in activities involving the manipulation of potentially infectious agents, samples or patients. Its objective is to avoid the release of the biological agent inside and outside the workplace, to protect the worker, the community or population, the environment (animals and plants) and the sample or process from contamination (INSST, 2020).

2 Individual or group of people with an interest in the operation or success of an organization. Examples: clients, staff and representatives, shareholders and owners, partners and suppliers, banks, unions, company, etc. (ISO, s, f).
}

In order to respond to customer requirements in this new context and managing the supply chain during the COVID19 pandemic, an unprecedented coordination and collaboration between processes, organizations, markets and the wider economy is required (Kumar et al. 2020).

To identify stakeholders and model this complex system, one of the most widely used tools is the value chain analysis, which provides a framework to identify the criteria to be considered in inventory management for decision making through all areas of the company (PovedaBautista et al. 2012; Nauhria et al. 2018). For this, it is vital to integrate stakeholders into teamwork, since they influence the successful implementation of strategies in a system (Elias 2019).

According to Verma and Gustafsson (2020) in the (relatively short) period of COVID-19, a relatively high number of articles have been published analyzing its impact and proposals in the field of business and management, in which the focus of traditional business proves not to be effective and different proposals are made according to defined clusters, which show that this stage will be a catalyst for short-, medium- and long-term policies in this area. In particular, the need to produce scientific literature on successful business practices in handling this uncertainty is analyzed. Particularly, inventory management, focused on maintaining low levels of optimized inventory, is ineffective in the environment of improbable high risk, but of great impact. Given that inventory processes are transversal to all clusters and considering that the current pandemic has made researchers propose a new definition for supply chain interruptions risks, the extraordinary risks, it is important to have literature that shows good practices.

In this sense, this article presents the experience of a Colombian SME, which produces and markets biosafety products and in order to respond to the changes generated in the demand for its products during the COVID-19 pandemic, required to analyze its processes, particularly the inventory and adapt it in order to maintain and/or improve compliance with customer service levels, hence the research question how to make the inventory management process more flexible, considering multiple criteria of the stakeholders with the goal of maintaining and/or improving the service level during the COVID-19 pandemic? The research is approached from a mixed methodological approach, due to the advantage of considering a multiplicity of observations that produce a "richer" and varied data, considering different sources and types of data (Hernández-Sampieri 2018).

The results obtained by applying adaptive strategies based on the integration of the stakeholders are included, through teamwork and interoperability, achieving the necessary flexibility in the decision-making process and 
guaranteeing the objective of maintaining and/or improving the customer service levels.

\section{Literature Review}

Several authors analyze the concept of supply chain, agreeing that it is a network of entities that are related to produce value in the form of products and services to the customer, through processes and activities from the initial supplier to the final customer, where they encounter numerous actors who interact through material, informational and financial flows (Albrecht 2009; Blanchard 2010; Clivillé and Berrah 2012).

The objective of a supply chain is to meet the customers' needs, and for this, within the supply chain management (SCM), special attention must be paid to the impact in the chain and selection of suppliers, information systems, the control and falsification of products, the links' scheme and simulation of processes, the network actors and the relationships between its members (Mikkola and Skjoett-Larsen 2003; Mani et al. 2016; Weenk 2019).

For the decisions analysis, in this complex system to fulfill the promise of value to the customer, Poveda-Bautista et al. (2012) using the value chain analysis approach are recommended. However, considering the multiple criteria of companies' people from different areas internal and external, can be complicated by having a diversity of objectives, knowledge, etc. These drawbacks can be mitigated if the stakeholders can be integrated into the decision-making process, since organizational theory and the change management literature argue that organizations are made up of different groups that have different values and objectives and considering their criteria and opinions tend to reduce conflicts (de Vries et al. 2018). Design principles for the stakeholder's engagement should consider (1) organization, (2) values, and (3) practices. The former help to focus on organizational objectives and identifying the necessary resources, values; encourage the commitment of participants in decisions and practices; creating flexibility within the decision process (Boaz et al. 2018; Shukla et al. 2019).

Inter-company relationships are formalized through contracts, which generally tend to focus on elements that each party includes to protect themselves, but in the current scenario it will be best to focus not on a business model focused on transactions, but on a business, model based on results. Where collaborative agreements lead to the creation of value through win-win solutions, as advised by the Vested Business Model (Vitasek et al. 2013; Vitasek and Ledyard 2013).

In this sense, customer demand and the pricing model are critical components of the supply chain, which has important implications for the business' strategic and operational objectives. This management must guarantee the stable availability of the products demanded by customers, coordinating the sale, production and distribution functions in intra- and inter-company relations in order to satisfy the target market at a rational cost and taking into account the processes' variability and uncertainty (Diaz et al. 2016).

The inventory management of multiple products is undoubtedly a decision problem that reaches high complexity levels, which must consider criteria of effectiveness and efficiency of the process and must answer key questions such as which customer to serve, which products and what quantities to deliver, why have a product in inventory, what quantity should be in inventory, among others (Singh et al. 2019). The answers should focus on achieving the organization's objectives and in reducing the intrinsic conflicts between roles, achieving a consensus between various areas and those responsible for the processes in functions such as sales, production employees, logistics and warehouse managers, among others, that undoubtedly generates a complex problem, since an inventory manager making unilateral decisions cannot have adequate results (de Vries 2020).

\section{Supply Chain's Risks}

A supply chain risk has been classified as an operational and disruption risk (Ivanov 2020). Operational risks are related to problems of quality, quantity and delivery times (Singh and Acharya 2013), which are predictable and controllable. The disruption's risks are known as those associated with catastrophes, which are less controllable (Ray and Jenamani 2016). They are characterized by the existence of impact risk for a long time, high uncertainty of future impacts and the domino effect of the event on other functions or processes (propagation of disturbances).

As a result of the current world situation, the importance of the implementation of Supply Chain Risk Management (SCRM) has increased, with a focus on interruption risks, also known as extraordinary risks. These types of risks are characterized by: universality; many sectors span, unpredictability; it is not known which regions will be affected, nor to what extent the activity will be limited, severity; due to the severe restrictions and total closures that are emphasizing the importance of the supply chain, in addition to what it was normally designed for, chain reaction; fearful of running out of supplies, states of emergency can force all manufacturing industries to reduce or scale shortterm production and supply, and ultimately stability; the longer the pandemic lasts, society will be economically damaged, causing late payments, defaults and an increase in the delinquency rate. In these terms, a question arises, 
how to stabilize a supply chain in times of turbulence or a VUCA world?

\section{Flexible Strategies in Order to Mitigate and Stabilize a Supply Chain}

To reduce risks in a chain, it must be taken into account whether if it is one or are multiple products.

Super flexibility is defined as the dynamic ability, to act quickly, and is organizationally focused (Evans and Bahrami 2020).

Koonin (2020) suggests updating and modifying the supply chain response strategies for a specific product, particularly when a significant disruption occurs, in order to ensure that companies can minimize the variance between the demand and supply.

Mitigation strategies for a simple product, for example, toilet paper, differ substantially from those that control other products, as they are not equally effective and applicable to all products in demand (Paul and Chowdhury 2020).

During the pandemic, inventory management has been very complex for biosecurity product trading companies, due to the variety of products, the impact on demand variations and the bullwhip effect, which has impacted on lead time and prices. Therefore, the strategies that are analyzed must consider these and other factors.

Inventory management risk mitigation strategies should be oriented to, (1) determination of the chain for materials management, (2) frequency of repositioning, 3) preservation of appropriate levels that can meet the demand, avoiding the decision to increase hedging inventory, which increases the probability of excess stock, obsolescence, expiration and deterioration.

The supply chain's main objective is to make decisions to achieve the desired level, for which the inventory management of multiple products studies shows several strategies:

- involving the stakeholders: alignment with organizational objectives, enrich and make the decision-making process more flexible (Boaz et al. 2018; de Vries et al. 2018; Elias 2019)

- the need to classify products: (1) selection of criteria in order to group the stock and focus on the control of the most important elements; (2) criteria rating, selecting the most appropriate method (methods such as ABC multicriteria, the hierarchical analytical process, among others (Flores and Whybark 1986; Lolli et al. 2017; Dos Santos et al. 2019; Eraslan and Ç 2019)). Each company can select the criteria, the classification method that best suits their conditions (Flores et al. 1992; Partovi and Burton 1993; Scala et al. 2013;
Gómez 2019), as well as the methods for defining the thresholds for classification (Hadad and Keren 2013; Hatefi et al. 2014)

- identifying the demand pattern and adjusting the forecasting model (Vidal Holguín 2010)

- identification and selection of the inventory control system (Vidal Holguín 2010; Pérez-Vergara et al. 2013; Gómez 2019)

Pérez Vergara et al. (2020) propose a combined ABC-AHP approach supported by teamwork, which involves all areas of the value chain, as a propitious framework for the improvement of distributed decision making in the inventory management, an approach that can be especially effective in managing current uncertainty, generating information exchange and participation in the decision making of interested parties, tending toward interoperability, in its organizational dimension.

Interoperability is an important element in management that supports the flexibility of operations, and it is considered the ability of an organization to act interoperable, both internally and externally, with a significant competitive advantage, since it can reduce costs, improve timely response and allow a greater scope of its operations. It is vital in the area of information systems, since it allows effective connections between companies that allow the exchange, interaction, collaboration and compatibility of inventory, transport, production and other information (Santiago et al. 2019). Based on this definition, specifically for inventory management, the unique identification of products at all packaging levels is crucial, supported among others by the ISO/IEC FDIS 15459-4: 2014 standard, which guarantees interoperability between information systems of the actors of the supply chain using the standards to communicate globally (Lopes-Martínez et al. 2018).

Inventory management under an environment of uncertainty and risk challenges the ability to analyze, interpret and search for solutions, requiring drastic decisions in real time that force the chain processes to be adjusted and more flexible.

Flexibility in inventory decisions to maintain a high level of customer service is vital to face the risk of epidemic outbreaks as COVID-19, which is classified by Ivanov (2020) as a unique type of supply chain risk. The actions of decision makers that allow faster recovery of operations in the supply chain have to be studied for their application in each supply chain tier at a medium and long term, but the literature that helps to face this scenario is still scarce (Carracedo et al. 2020). The unpredictable scaling, the ripple effect in the supply chain and the uncertainty regarding the effective development, production, distribution and application of vaccines, which is the element that 
is looming as a solution, are not exempt from uncertainty, taking into account previous experiences (El Baz and Ruel 2020; Fausther-Bovendo and Kobinger 2020; Mustapha et al. 2020).

In order to address the decisions of the multiple products to be managed is required a method to obtain a products classification in the inventory taking into account the criteria provided by the interested parties, the selection of the most appropriate classification method, considering various factors, which is part of the decision process' structure (Lolli et al. 2017; Dos Santos et al. 2019; Gómez 2019).

\section{Case Study}

The company selected for this study meets the demand for products in different market segments in Colombia (health, beauty, food handling, etc.) that ensure the required biosecurity under current conditions. It is classified as SME, with 100 workers. It has ISO 9001 certification and with the National Institute of Medicine and Food of Colombia (INVIMA), on sanitary conditions, storage and conditioning. The company also has operations in Ecuador and Panama, with a view to being present in the segments in four Latin American countries, doubling its operating result, generating economic and social value. Its product portfolio handles $63 \%$ of the products imported finished products, which are grouped into eight families and in twenty product groups. The planning process, which includes the management and control of inventories and the quantities to be requested for their supply, is considered one of the most important, being located within the operational processes of the process map in the logistics area.

\section{Research Focus}

COVID-19 imposed a new world scenario in which biosecurity protocols were established, reflected in policies adopted by different countries, which impacted the company's demand, more directly the inventory process.

The investigation began in December 2019, the date on which Colombia began to prepare to assimilate the effect of COVID-19 and the company visualized the need to analyze actions to confront it.

A methodology with a mixed approach was adopted, developing the research through a before-after study of a single group that is based on the measurement and comparison of the response variable before and after the subject's exposure to the experimental intervention (Hernández-Sampieri 2018).

The investigation's objective was aligned with the company's mission, to maintain or improve service levels reducing the risks of inventory failures. Considering the criterion of super-flexibility (Evans and Bahrami 2020), such as the dynamic capacity, to act quickly and focus on the organization, in each phase of the inventory process, adaptive strategies focused on mitigating a specific risk scenario were identified and proposed, implementing an agile approach for a defined time horizon, thus addressing the research problem. Decisions involving sectors, clients, products, forecasting method to be adopted, inventory control model, suppliers, among others, were considered.

\section{The Situation Before COVID-19}

The company groups its clients into consumers, wholesalers and distributors, defining the commercial policy for each one. It knows the demand and manages the products through imports from eight suppliers with individual contractual characteristics, such as delivery time, that guarantee the availability of the products.

The process manages a service-level indicator, which is calculated using Eq. (1) (Ballou 2004).

Fill Rate $=\frac{\text { Total number of customer orders shipped }}{\text { Number of customer orders filled }} 100$

The goal that the company manages for the fill rate indicator is $95 \%$, and at the end of the second half of 2019, it showed a compliance of $95.5 \%$, as shown in Fig. 1 .

In the previous period to COVID-19, the company managed its inventory using a management model, with a five-phase structure, as shown in Fig. 2.

- Phase 1-Integration of the teamwork, criteria selection, and classification.

- Phase 2-Multicriteria ABC inventory classification

- Phase 3-Analysis of demand behavior

- Phase 4-Demand forecasting

- Phase 5-Inventory control systems

\section{Situation During COVID-19}

The company faces a situation of exponential increase in demand, resulting from the real need and compulsive behavior of customers in the distribution channel, which leads to a bullwhip effect on security products. Disruption in the supply market threatened the ability to meet orders with a high service level.

The company kept the objective of maintaining the goal of the fill rate indicator at $95 \%$, for which it decided to analyze how to make the supply chain more flexible, attending to the effects that affect each link in the chain.

As a result of the pandemic and the market response, the reality was that the inventory and production capacity of the products with the highest demand were not enough to satisfy the orders of all customers. 
Fig. 1 Behavior of the service level in the second half of 2019

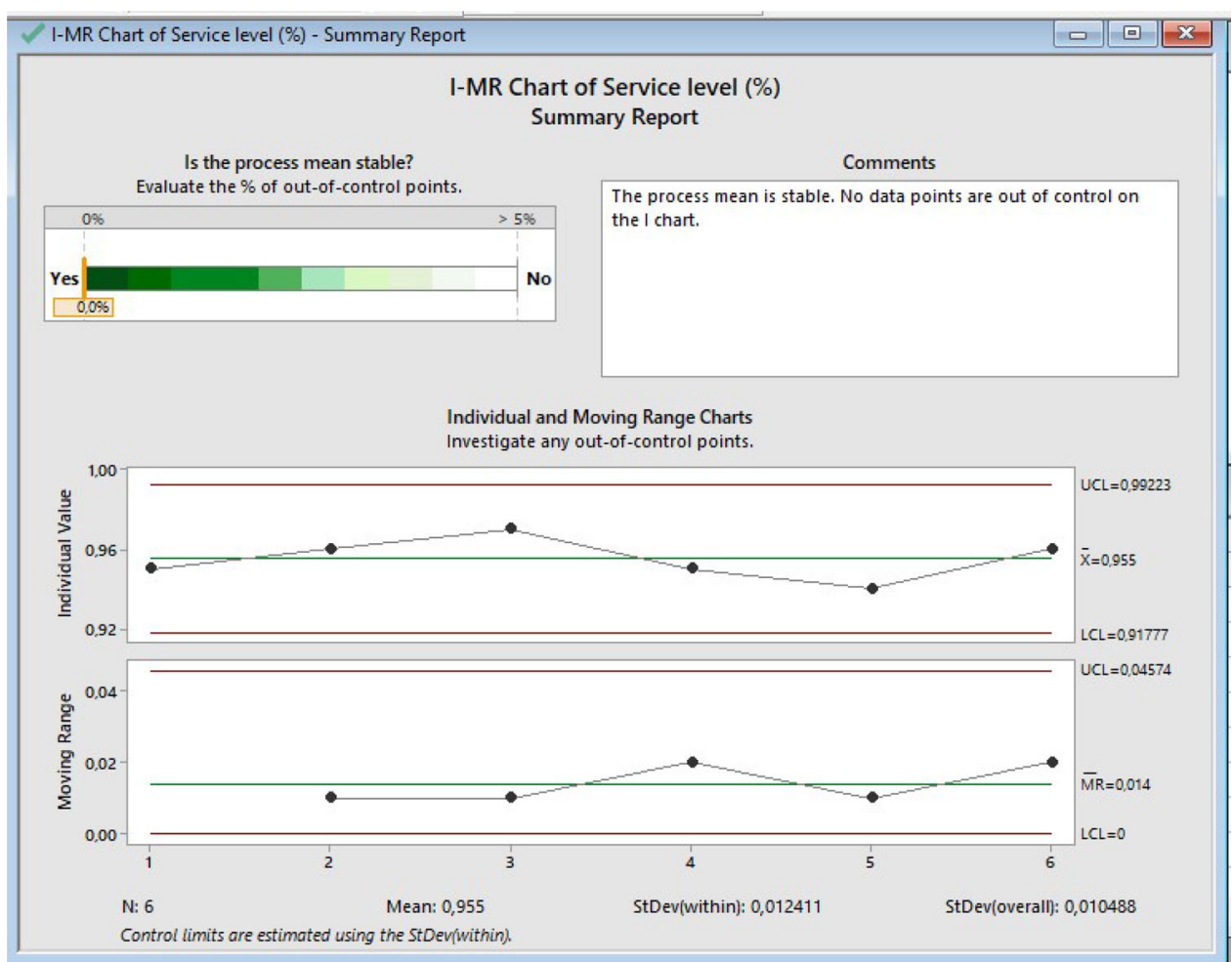

Three strategies for the flexibility of the chain and its processes were analyzed.

\section{Strategy 1. Strengthen the Communication Between Stakeholders}

The main objective was to consider the interest of the stakeholders in the decision-making stage in order to enrich the analyses, make decisions more flexible and reduce intrinsic conflicts between stakeholders (de Vries et al. 2018; Elias 2019).

A multi-expert multi-criteria framework is proposed for inventory management, considering that multi-criteria decision analysis provides the necessary flexibility to achieve integration, a greater commitment throughout the supply chain, which is guaranteed through greater interoperability between the links (Pérez Vergara et al. 2020).

\section{Strategy 2. Customer Prioritization}

The prioritization of customers is part of the supply chain flexibility strategies (Singh et al. 2019), and it is adapted for a trading company, where it considers that sharing resources between different types of customers means distributing proportionally according to an agreement and setting priorities. It was proposed to meet demands aligned with the policies issued by the Ministry of Health in Colombia.
Strategy 3. The Size of the Order is Decided by the Customer

In this scenario, it is not possible to accurately forecast the demand pattern using theoretical models, and the available historical information is not reliable. This strategy is based on the supplier-retailer relationship and the concept of strategic inventory, which can benefit both parties. Strategic inventory states that the supplier determines a wholesale price at each stage and the retailers/customers decide the order quantity. This strategy is based on what is proposed by Koonin (2020) who establishes that business alliances can be used as a recovery plan for COVID-19.

With a focus on continuous improvement based on these three strategies, adjustments were proposed to the inventory control model used by the company, to manage the process under the new conditions during the COVID-19 period.

Figure 3 shows the changes in the model, mainly produced in phases 1,3 and 5 .

\section{Results}

The adjusted model began to be implemented in January 2020, and the results show the real behavior of the company's inventory compared in two periods, (before COVID-19) second half of 2019 vs (during COVID-19) 


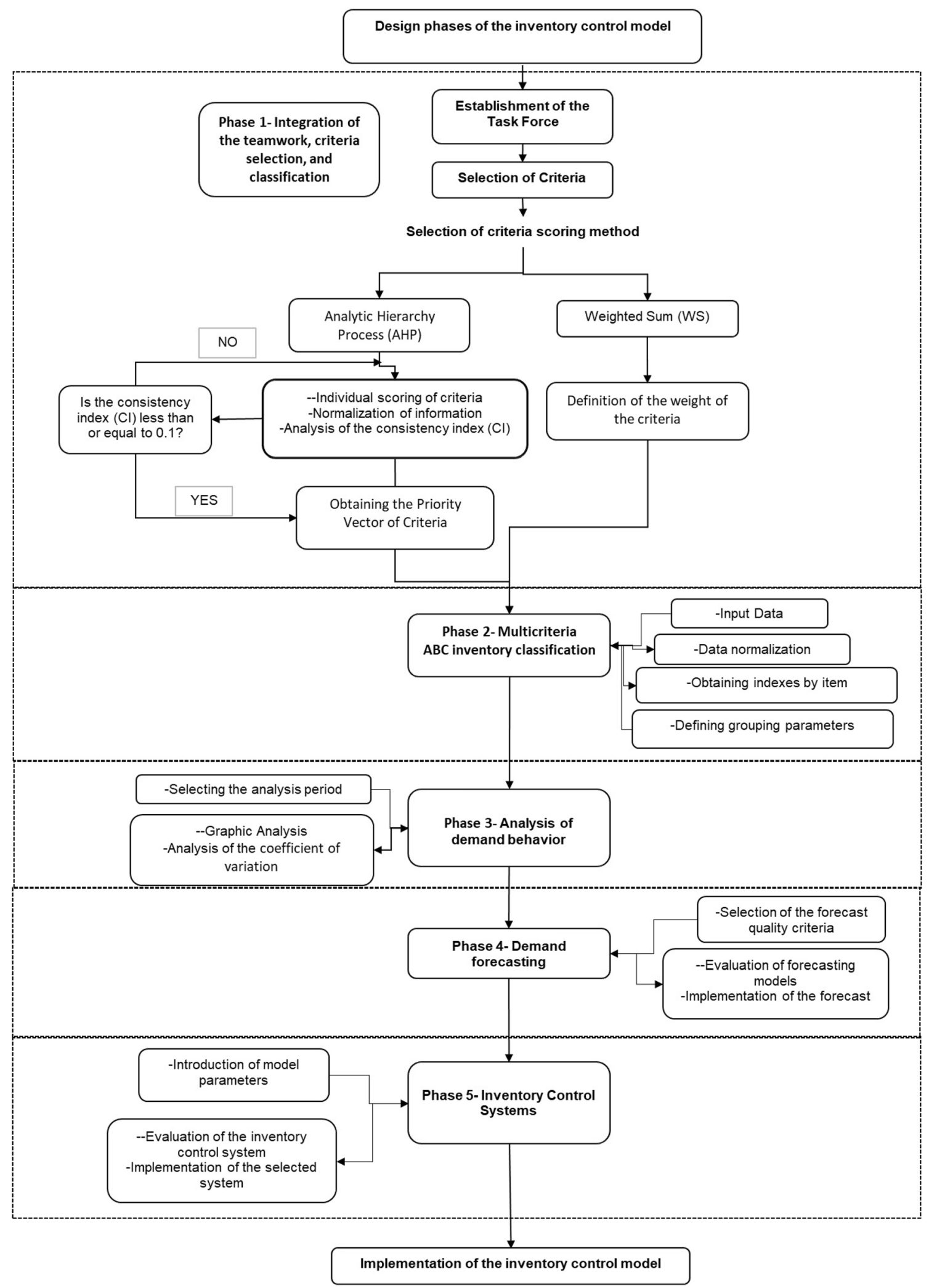

Fig. 2 Inventory control model before COVID-19 (Gómez 2019) 


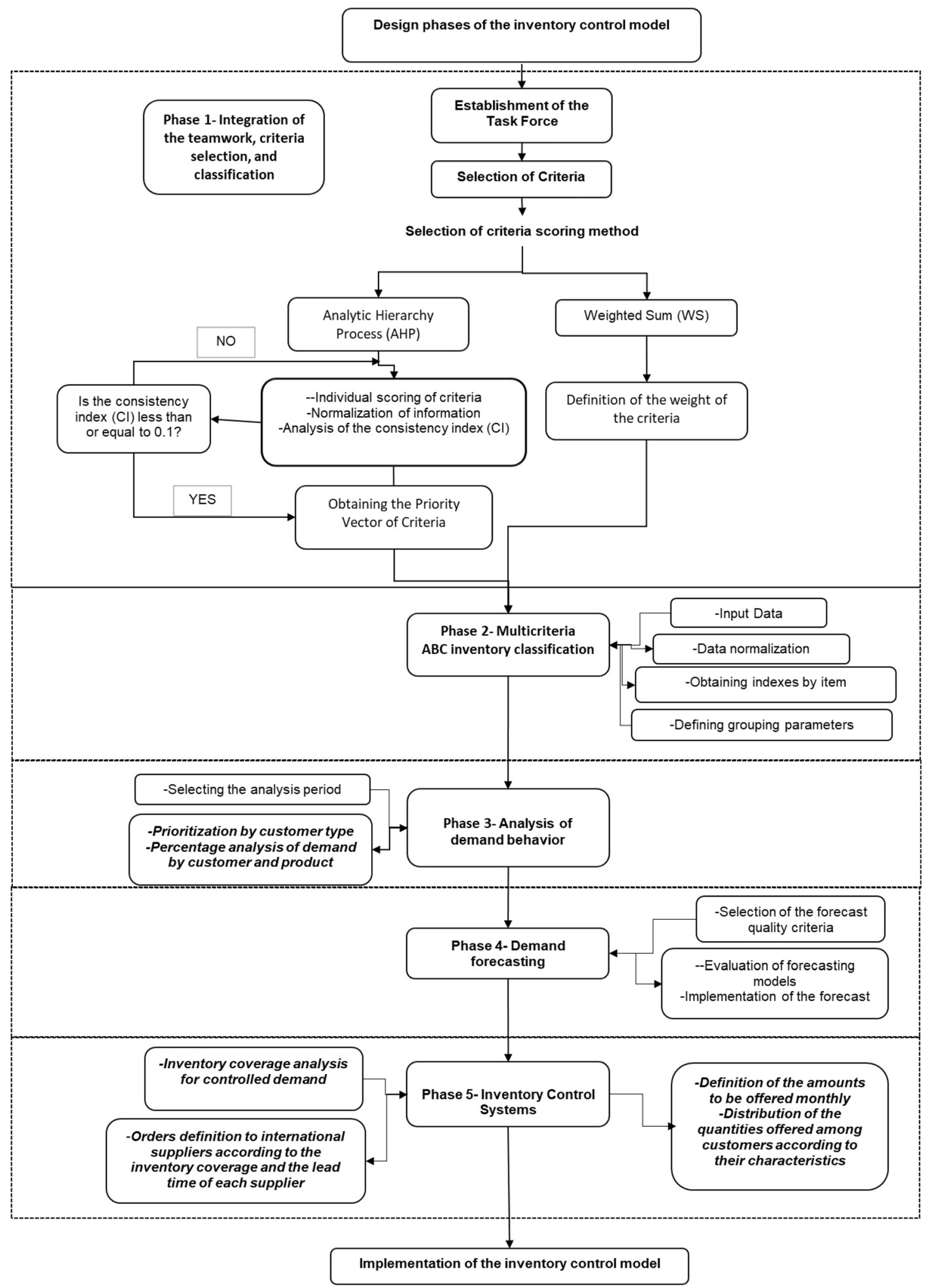

Fig. 3 Inventory control model during COVID-19 
first half of 2020, taking into account the joint impact of the strategies.

\section{Strategy 1. Strengthen the Communication Between Stakeholders}

Teamwork contributes to expedited communication between stakeholders for decision making on company demand during the pandemic, increasing, among other things, the visibility of inventory in the supply chain to mitigate the bullwhip effect. This strategy allowed expanding the Phase 1 Working Group, integrating all stakeholders and improving the communication process, through interoperability. The composition of the work team before and during COVID-19 is shown in Fig. 4.

The team analyzed two alternatives to mitigate and control the effects on the supply chain and make the inventory process more flexible:

1. Sell all products directly related to orders, increasing the price of products with high demand and low supply, and with it, increasing speculation on prices.

2. Increase collaboration within the supply chain and try to satisfy each customer at a reasonable level with the real capacity of the company and the supply chain.

By consensus, the company's social responsibility was prioritized, and alternative 2 was decided.

To classify the products, the work team selected the criteria and through the implementation of the AHP method, the selected ABC classification criteria were: Outstanding Days of Inventory (DIO), Unit Cost, and Lead Time, corresponding with the criteria that the company previously worked (Gómez 2019). The grouping parameters were defined according to the indices per item using Eq. 2 (Zuluaga et al. 2011), and the results found 17 items classified as type A products, including them as essential products for the pandemic.

$$
\text { Index } \text { by item }=\sum_{i=1}^{I} \mathbf{W}_{j} \mathbf{y n}_{i j}
$$

where

- $\mathbf{W}_{j}$ is the priority vector value for the $\mathrm{j}$ criteria.

- $\mathbf{y n}_{i j}$ is the normalized item value according to the criteria

The incorporation of stakeholders in decision making allowed a reliable and timely flow of information and decision making and improved the balance between social responsibility and the company's economic result, making flexible the management of the inventory process and the supply chain. Considering customer satisfaction as a goal and social responsibility as an alternative, the team analyzed other strategies to manage the crisis generated by COVID-19.

\section{Strategy 2. Customer Prioritization}

According to the regulatory policies issued by the Ministry of Health in Colombia during COVID-19, biosafety product companies must give priority to the customer over wholesalers and distributors, to bring the products closer to the population. This was reflected in the structure of demand by product family, customer types and segment, as shown in Fig. 5, where the green highlight refers to a new commitment and in red, the effects due to low demand.

The families of personal protective equipment (PPE) and caps are included in the health sector, while pharmacies appear as new customers, and the demand for caps decreases in food handling due to new government policies.
Fig. 4 Comparison of teamwork members for inventory management decisions in Phase 1
Before COVID-19

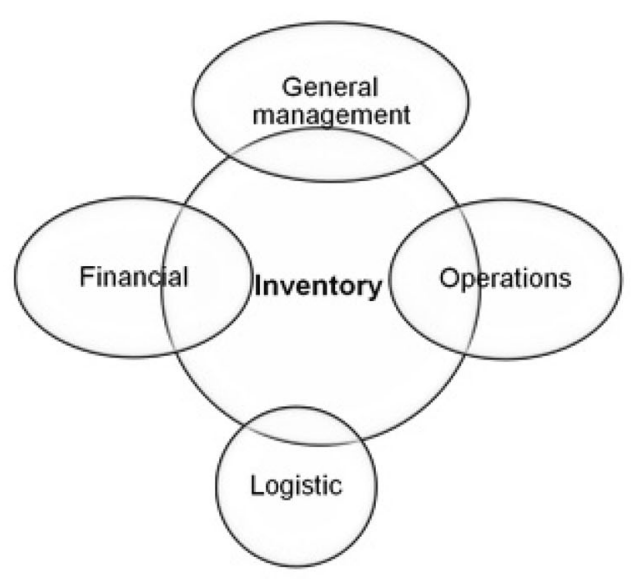

During COVID -19

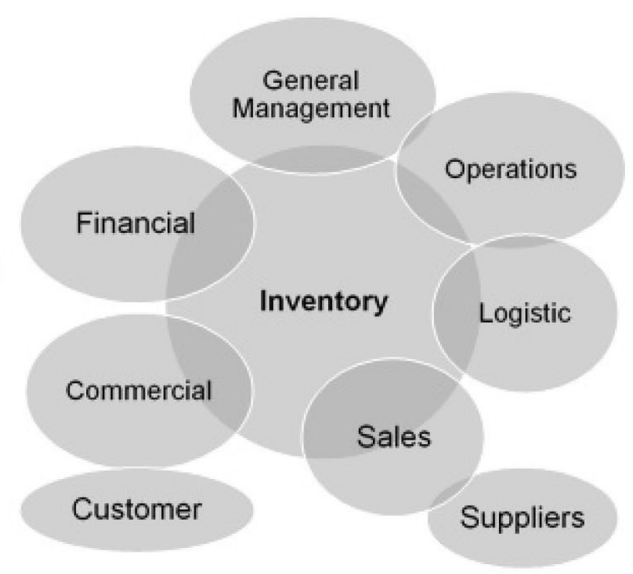




\begin{tabular}{|c|c|c|c|c|}
\hline \multirow{2}{*}{ Items family } & \multicolumn{2}{|c|}{ Before COVID-19 } & \multicolumn{2}{|c|}{ During COVID-19 } \\
\hline & Segment & Customer type & Segment & Customer type \\
\hline \multirow{2}{*}{$\begin{array}{l}\text { Personal protection } \\
\text { equipment (PPE) }\end{array}$} & Manufacturers & Consumer & Manufacturers & Consumer \\
\hline & & & Healthcare & Consumer \\
\hline Fogging machine & Healthcare & Distributor & Healthcare & Distributor \\
\hline Gauze and compresses & Healthcare & Consumer & Healthcare & Consumer \\
\hline \multirow{3}{*}{ Surgical caps } & Healthcare & $\begin{array}{l}\text { Consumer and } \\
\text { distributor }\end{array}$ & Healthcare & Consumer \\
\hline & Manufacturers & Consumer & Manufacturers & Consumer \\
\hline & Food handling & $\begin{array}{l}\text { Consumer and } \\
\text { distributor }\end{array}$ & & \\
\hline \multirow{5}{*}{ Gloves } & Healthcare & $\begin{array}{l}\text { Consumer and } \\
\text { distributor }\end{array}$ & Healthcare & $\begin{array}{l}\text { Consumer and } \\
\text { distributor }\end{array}$ \\
\hline & Manufacturers & Consumer & Manufacturers & Consumer \\
\hline & Beauty & $\begin{array}{l}\text { Consumer and } \\
\text { distributor }\end{array}$ & Beauty & $\begin{array}{l}\text { Consumer and } \\
\text { distributor }\end{array}$ \\
\hline & Food handling & $\begin{array}{l}\text { Consumer and } \\
\text { distributor }\end{array}$ & Food handling & $\begin{array}{l}\text { Consumer and } \\
\text { distributor }\end{array}$ \\
\hline & & & Drugstores & Distributor \\
\hline $\begin{array}{c}\text { DISPOSABLE } \\
\text { POLYETHYLENE } \\
\text { PROTECTION ELEMENTS }\end{array}$ & Manufacturers & $\begin{array}{l}\text { Consumer and } \\
\text { distributor }\end{array}$ & Manufacturers & $\begin{array}{l}\text { Consumer and } \\
\text { distributor }\end{array}$ \\
\hline \multirow{5}{*}{ Masks } & Healthcare & $\begin{array}{l}\text { Consumer and } \\
\text { distributor }\end{array}$ & Healthcare & $\begin{array}{l}\text { Consumer and } \\
\text { distributor }\end{array}$ \\
\hline & Manufacturers & Consumer & Manufacturers & Consumer \\
\hline & Drugstore & Distributor & Drugstores & Distributor \\
\hline & Beauty & $\begin{array}{l}\text { Consumer and } \\
\text { distributor }\end{array}$ & Beauty & $\begin{array}{l}\text { Consumer and } \\
\text { distributor }\end{array}$ \\
\hline & Food handling & $\begin{array}{l}\text { Consumer and } \\
\text { distributor }\end{array}$ & Food handling & $\begin{array}{l}\text { Consumer and } \\
\text { distributor }\end{array}$ \\
\hline Polyethylene Gloves & Food handling & $\begin{array}{l}\text { Consumer and } \\
\text { distributor, and } \\
\text { wholesaler }\end{array}$ & Food handling & $\begin{array}{l}\text { Consumer and } \\
\text { distributor, and } \\
\text { wholesaler }\end{array}$ \\
\hline
\end{tabular}

Fig. 5 Impact of prioritization by types of clients

The flexible approach was ensured by the integration of the stakeholders in a scenario of both parties doing business by cooperation, to establish a balance between customer satisfaction and the economic impact for the company, in a win-win environment.

Favored by government policies, with the main objective of serving the general public, taking care of the population's health, the highest growth in sales has been in pharmacies, followed by health institutions. Later, EPP sales to manufacturing plants experienced significant growth, due to the restructuring of the biosafety protocols that they had to implement, inducing an increase in purchase volume, evidenced in the stock.

Figure 6 shows the impact of the product sales segment by sector or customer group, showing the highest percentage of growth in the pharmacy and health segments, achieving the main objectives of the strategy.

\section{Strategy 3. The Size of the Order is Decided by the Customer}

The COVID-19 Essential Supplies Forecasting Tool (WHO 2010) was taken as a reference for the input information 


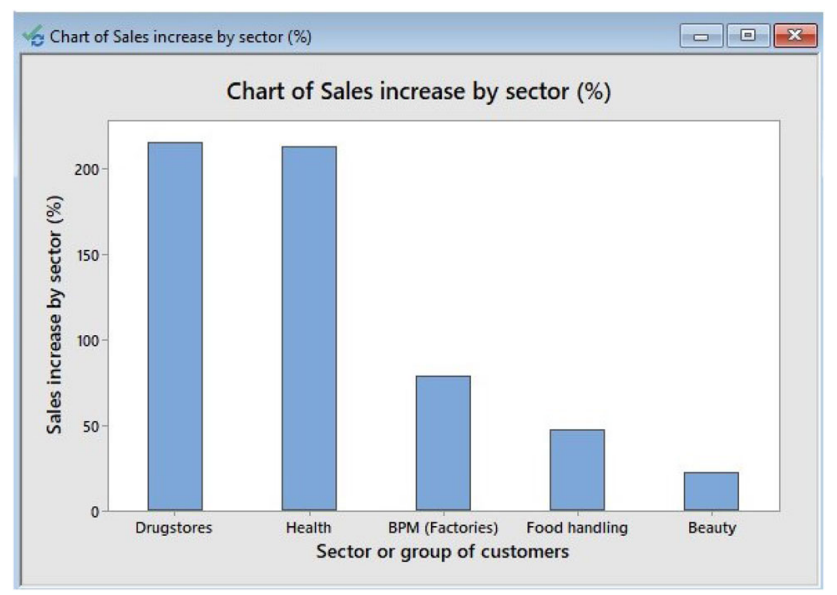

Fig. 6 Impact of the product sales segment by sector or customer group

according to pandemic behavior in Colombia. Focusing on type A items, demand was carefully analyzed and criteria were collected from stakeholders, directly determining future demand based on customer interaction.

An average demand per client was set, and according to its history and the projection of consumption in the new conditions, a periodic review system was implemented, which facilitates the simultaneous coordination of various items, achieving significant economies of scale (Ballou 2004; Vidal Holguín 2010). Figure 7 shows as an example, the contrast between the demand for masks, before and during the pandemic.

As shown in Fig. 7, in February (month 2), the highest peak in demand for masks occurred, coinciding with the announcement of the arrival of the virus in Colombia, and later the demand was maintained until March, when the first case of COVID-19. A perpetual demand was used for the use of average requirements, prioritization and

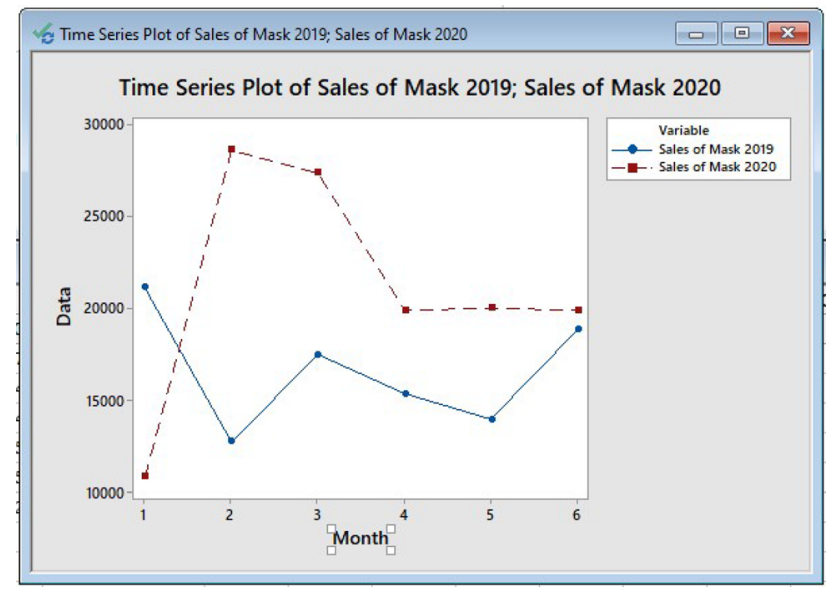

Fig. 7 Total sales of masks including COVID-19 period, in boxes of 50 units alignment with government regulations, avoiding speculation and hoarding of inventories and prices. The perpetual demand decision was initially set for a 7-month horizon, which allowed aligning the entire process with external suppliers, considering service levels, sales projections and inventory levels for the forecast for 2021. Maintaining vigilance over the pandemic, the company analyzes continuous decisions and foresees for the next period, after the pandemic, to consider an erratic demand, following the same methods and variables of the inventory control model prior to COVID-19.

Another factor of high impact was the variation in the delivery times of the suppliers, taking into consideration that $63 \%$ of the articles are imported, and the variation of said time is shown in Fig. 8.

This behavior evidenced a statistically significant increase in the average number of supply days, which made it necessary to assess the inclusion of four (4) new international suppliers to cushion the variation in the impact on the supply and demand relationship, since until June 2020, the supply market in Colombia did not meet the quality requirements of the products, demanded by the company to become an alternative.

\section{Measurement of the Effectiveness of the Strategies}

With the level of service being the objective of the study, Fig. 9 shows the comparative behavior of the impact of the combined application of the strategies, in a process capacity analysis graph.

The results show a slight increase in the service level of $0.7 \%$, this increase does not have statistical support; however, it shows the fulfillment of the research objective, achieving the promise of value for the client. This result is especially important because it confirms that the flexibility and adaptation decisions adopted by the company were capable of satisfying the contracted demand in this shortage scenario, guaranteeing the need of both the supplier and the customer. At the same time, the effectiveness of the strategies adopted is shown not only in improving the service level of orders, but also impacted other key performance indicators (KPI) such as Days of Inventory Outstanding (DIO), which it ranged from 144.5 to 121 days, which is shown in Fig. 10.

Likewise, the flexibility introduced to the inventory process to adapt to the new conditions imposed by COVID19, in addition to demonstrating compliance with the objective of the investigation, maintaining or improving the customer service level, showed an economic impact by reducing the $19 \%$ of Average Monthly Inventory Cost, shown in Fig. 11. 
Fig. 8 Impact of COVID-19 on the delivery time of suppliers

Fig. 9 Comparison of the service level before and after the strategies were applied
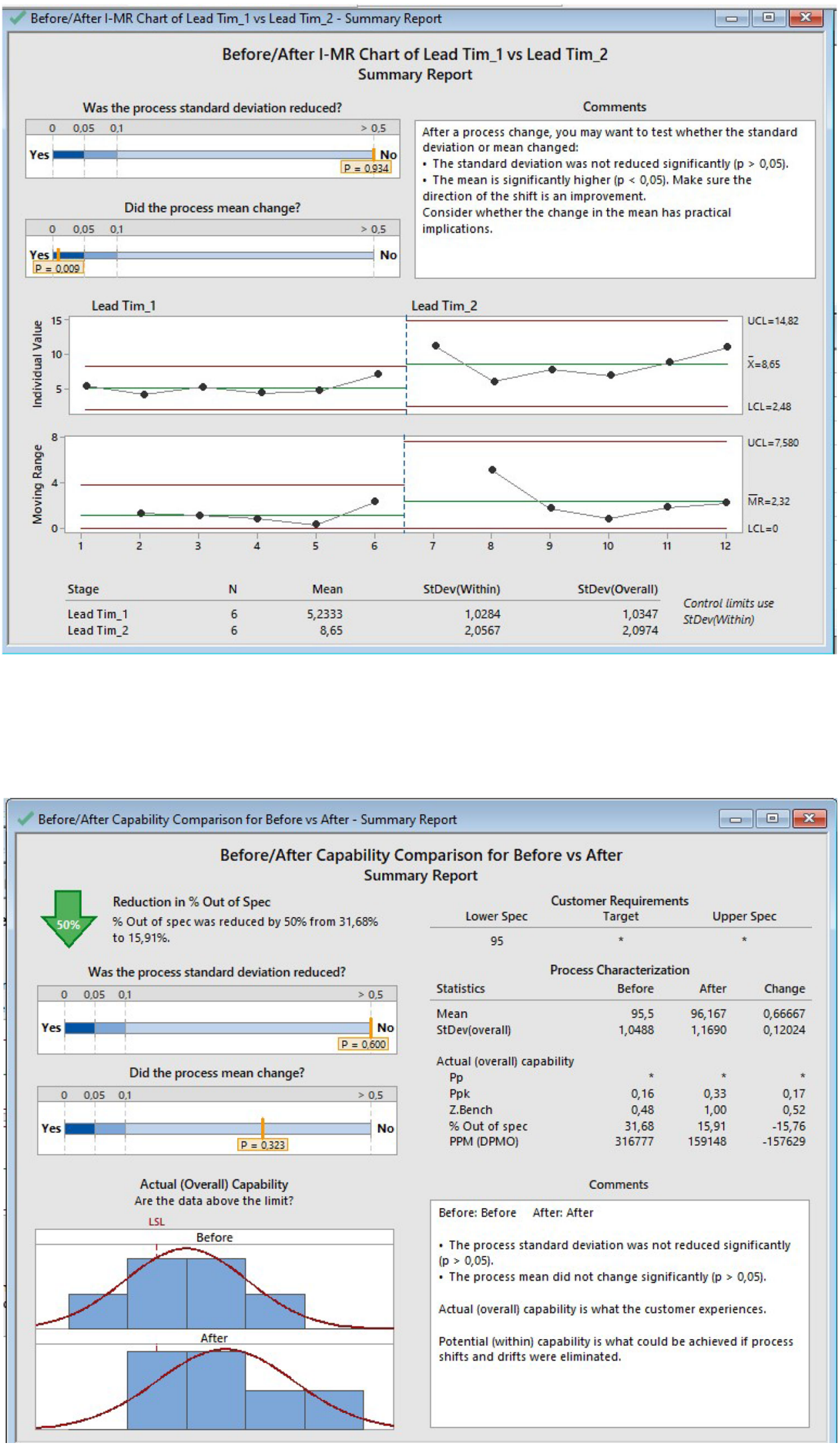


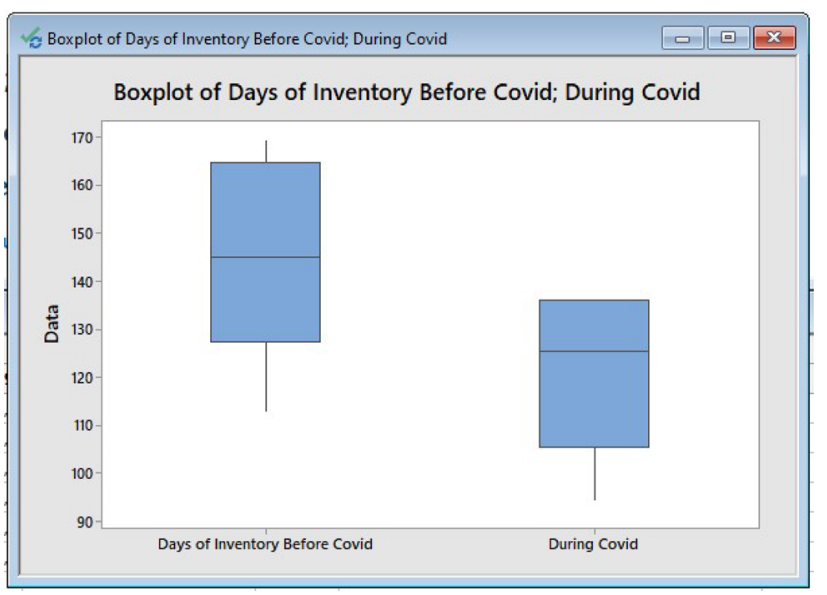

Fig. 10 Days of Inventory Outstanding (DIO)

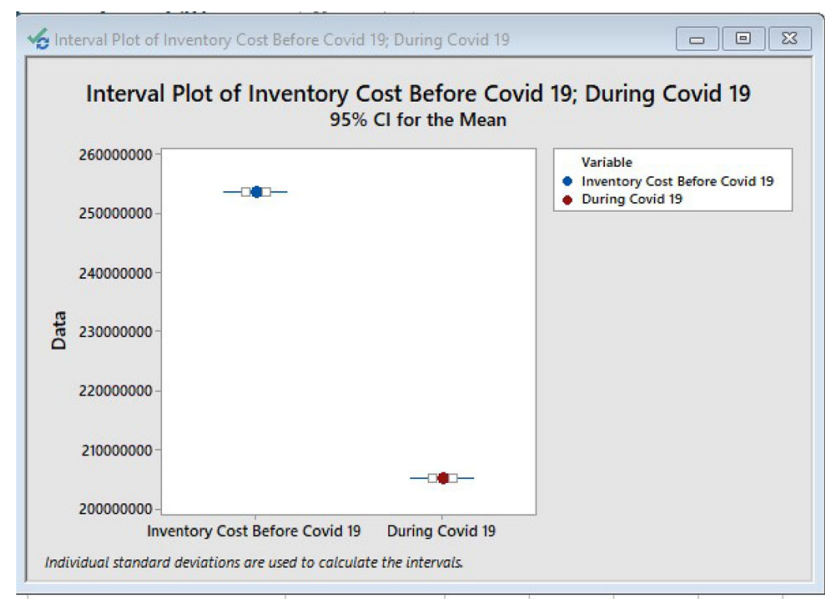

Fig. 11 Comparison of the average monthly cost before and during COVID-19

\section{Conclusions and Future Work}

In the conditions of uncertainty generated by the COVID19 pandemic, which generated a global disruption of supply chains that led to inventory shortages, the objective of companies must continue to be to serve the voice of the customer.

The decision-making process was strengthened by involving stakeholders, which increased visibility and communication through the supply chain actors based on a cooperative approach that allowed ensuring results through a win-win approach and safeguard sustainable results in this scenario.

The management of the inventory process was visualized by maintaining and/or improving its performance indicators, in this case the Fill Rate, achieved through a change of focus oriented to sales (\$), before COVID-19, to one of prioritizing social responsibility, managing to maintain the service levels of high-demand items, such as those prioritized by the World Health Organization for the preservation of life during the COVID-19 crisis.

The research showed that it is possible to implement strategies that make the processes more flexible to adapt to market conditions, theory and practice, articulating experience and knowledge, achieved in this case in a better way through teamwork, applying methods such as ABC classification for multi-product and multi-criteria inventories, the AHP method, which allowed aligning the results of the research with the organization's objectives.

The results obtained with real data from the biosafety company show that the proposed strategies were effective because they improved not only the service-level indicator with the highest order fulfillment rate, but at the same time, the Days of Inventory Outstanding (DIO) and the capital invested in inventory, guaranteeing essential and high-demand items closer to the consumer.

The model, its application and the proposed strategies, may be useful for other production and retail companies with many items in inventory in this context. The research assesses two key elements for success in a pandemic or similar scenario: the silos mentality present in companies must be broken, leading to the adoption of a holistic and cooperative approach by people; the COVID-19 experience shows that inventory optimization is not the best roadmap in all cases.

Inventory management is not only a mathematical and quantitative approach, and it has a great qualitative and organizational component, that is why technology alone will not solve the necessary flexibility that is required, the human being is a vital part of this chain of decisions (Winkelhaus and Grosse 2020).

Training of people in the supply chain has to focus on breaking the silo mentality present in companies that affects both their individual performance and that of the supply chain. COVID-19 has shown the need to transform traditional training both in the academic field and in the industry for an active and experiential learning by simulating various risk scenarios (Seow et al. 2019; Contador et al. 2020; Pekkanen et al. 2020).

\section{Limitations}

Although this study provides relevant elements, it also has some restrictions.

The main limitation of the study is that it is based on the observed experience of a company over a limited period of time.

Although the results are considered to be generalized, it is possible that under conditions other than this they may not be the most suitable if the objective is optimization. 
Acknowledgements We would like to thank the reviewers for their appreciated and exceptional contribution by providing critical feedback and comments to improve the manuscript. We would like to thank the editors and editor-in-chief for their encouragement and background for keeping the paper in this level of quality.

Funding No funding was received to assist with the preparation of this manuscript.

\section{Declarations}

Conflict of interest The authors hereby declare that there are no potential conflicts of interest in terms of authorship, research and/or publication of this article.

\section{References}

Albrecht, M. (2009). Supply chain coordination mechanisms: New approaches for collaborative planning (Vol. 628). Berlin Heidelberg, Germany: Springer Science \& Business Media.

Aldrighetti, R., Zennaro, I., Finco, S., \& Battini, D. (2019). Healthcare supply chain simulation with disruption considerations: A case study from northern Italy. Global Journal of Flexible Systems Management, 20(1), 81-102.

Ballou, R. H. (2004). Logiśtica: Administración de la cadena de suministro. México: Pearson Educación.

Blanchard, D. (2010). Supply chain management best practices. Hoboken, New Jersey: John Wiley \& Sons.

Boaz, A., Hanney, S., Borst, R., O'Shea, A., \& Kok, M. (2018). How to engage stakeholders in research: design principles to support improvement. Health Research Policy and Systems, 16(1), 60.

Carracedo, P., Puertas, R., \& Marti, L. (2020). Research lines on the impact of the covid-19 pandemic on business. A text mining analysis. Journal of Business Researchhttps://doi.org/10.1016/j. jbusres.2020.11.043, https://www.sciencedirect.com/science/arti cle/pii/S0148296320307967

Clivillé, V., \& Berrah, L. (2012). Overall performance measurement in a supply chain: Towards a supplier-prime manufacturer based model. Journal of Intelligent Manufacturing, 23(6), 2459-2469.

Contador, J. C., Satyro, W. C., Contador, J. L., de Mesquita, Spinola M., et al. (2020). Flexibility in the brazilian industry 4.0: Challenges and opportunities. Global Journal of Flexible Systems Management, 21, 15-31.

de Vries, H., Tummers, L., \& Bekkers, V. (2018). A stakeholder perspective on public sector innovation: Why position matters. International Review of Administrative Sciences, 84(2), 269-287.

de Vries, J. (2020). Identifying inventory project management conflicts: Results of an empirical study. International Journal of Production Economics p 107620

Diaz, R., Bailey, M. P., \& Kumar, S. (2016). Analyzing a lost-sale stochastic inventory model with markov-modulated demands: A simulation-based optimization study. Journal of Manufacturing Systems, 38, 1-12.

Dos Santos, P. H., Neves, S. M., Sant'Anna, D. O., de Oliveira, C. H., \& Carvalho, H. D. (2019). The analytic hierarchy process supporting decision making for sustainable development: An overview of applications. Journal of Cleaner Production, 212, 119-138.

El Baz, J., \& Ruel, S. (2020). Can supply chain risk management practices mitigate the disruption impacts on supply chains' resilience and robustness? evidence from an empirical survey in a covid-19 outbreak era. International Journal of Production
Economics, 233, 107972. https://doi.org/10.1016/j.ijpe.2020. 107972.

Elias, A. A. (2019). Strategy development through stakeholder involvement: A New Zealand study. Global Journal of Flexible Systems Management, 20(4), 313-322.

Eraslan, E., \& Ç YT., (2019). An improved decision support system for abc inventory classification. Evolving Systems, 11, 683-696.

Evans, S., \& Bahrami, H. (2020). Super-flexibility in practice: Insights from a crisis. Global Journal of Flexible Systems Management, 21(3), 207-214.

Fausther-Bovendo, H., \& Kobinger, G. (2020). Vaccine innovation spurred by the long wait for an ebola virus vaccine. The Lancet Infectious Diseaseshttps://doi.org/10.1016/S14733099(20)30515-6, https://www.sciencedirect.com/science/arti cle/pii/S1473309920305156

Flores, B. E., \& Whybark, D. C. (1986). Multiple criteria ABC analysis. International Journal of Operations \& Production Management, 6(3), 38-46.

Flores, B. E., Olson, D. L., \& Dorai, V. (1992). Management of multicriteria inventory classification. Mathematical and Computer modelling, 16(12), 71-82.

Gómez, M. C. L. (2019). Diseño de un modelo para el control de los inventarios para el mejoramiento del nivel de servicio del "cumplimiento de pedidos" en una empresa de productos para la bioseguridad. http://biblioteca.usbcali.edu.co/cgi-olib/?infile= details.glu\&loid $=226977 \& \mathrm{rs}=1563031 \&$ hitno $=1$

Hadad, Y., \& Keren, B. (2013). Abc inventory classification via linear discriminant analysis and ranking methods. International Journal of Logistics Systems and Management, 14(4), 387-404.

Hatefi, S., Torabi, S., \& Bagheri, P. (2014). Multi-criteria abc inventory classification with mixed quantitative and qualitative criteria. International Journal of Production Research, 52(3), 776-786.

Hernández-Sampieri CPM Roberto Torres. (2018). Metodología de la investigación. McGraw-Hill Interamericana Editores, S.A: de C.V., D.F., México.

Ivanov, D. (2020). Predicting the impacts of epidemic outbreaks on global supply chains: A simulation-based analysis on the coronavirus outbreak (covid-19/sars-cov-2) case. Transportation Research Part E: Logistics and Transportation Review, 136, 101922.

Koonin, L. M. (2020). Novel coronavirus disease (covid-19) outbreak: Now is the time to refresh pandemic plans. Journal of Business Continuity \& Emergency Planning, 13(4), 1-15.

Kumar, A., Luthra, S., Mangla, S. K., \& Kazançoğlu, Y. (2020). Covid-19 impact on sustainable production and operations management. Sustainable Operations and Computers, 1, 1-7.

Lolli, F., Ishizaka, A., Gamberini, R., Balugani, E., \& Rimini, B. (2017). Decision trees for supervised multi-criteria inventory classification. Procedia Manufacturing, 11, 1871-1881.

Lopes-Martínez, I., Paradela-Fournier, L., Rodríguez-Acosta, J., Castillo-Feu, J. L., Gómez-Acosta, M. I., \& Cruz-Ruiz, A. (2018). The use of gs1 standards to improve the drugs traceability system in a $3 \mathrm{pl}$ logistic service provider. Dyna, 85(206), 39-48.

Lu, D., Ding, Y., Asian, S., \& Paul, S. K. (2018). From supply chain integration to operational performance: The moderating effect of market uncertainty. Global Journal of Flexible Systems Management, 19(Suppl 1), S3-S20.

Mani, V., Agrawal, R., \& Sharma, V. (2016). Impediments to social sustainability adoption in the supply chain: An ISM and MICMAC analysis in Indian manufacturing industries. Global Journal of Flexible Systems Management, 17(2), 135-156.

Mikkola, J. H., \& Skjoett-Larsen, T. (2003). Early supplier involvement: Implications for new product development, outsourcing 
and supplier-buyer interdependence. Global Journal of Flexible Systems Management, 4(4), 31-41.

Mustapha, J. O., Adedokun, K. A., Nasir, I. A., et al. (2020). Public health preparedness towards covid-19 outbreak in nigeria. Asian Pacific Journal of Tropical Medicine, 13(5), 197.

Nauhria, Y., Kulkarni, M. S., \& Pandey, S. (2018). Development of strategic value chain framework for Indian car manufacturing industry. Global Journal of Flexible Systems Management, 19(Suppl 1), S21-S40.

Partovi, F. Y., \& Burton, J. (1993). Using the analytic hierarchy process for abc analysis. International Journal of Operations \& Production Management, 13(9), 29-44.

Pastore, E., Alfieri, A., Zotteri, G., \& Boylan, J. E. (2020). The impact of demand parameter uncertainty on the bullwhip effect. European Journal of Operational Research, 283(1), 94-107.

Paul, S. K., \& Chowdhury, P. (2020). Strategies for managing the impacts of disruptions during covid-19: An example of toilet paper. Global Journal of Flexible Systems Management, 21(3), 283-293.

Paul, S. K., Sarker, R., \& Essam, D. (2013). A disruption recovery model in a production-inventory system with demand uncertainty and process reliability. In: IFIP International Conference on Computer Information Systems and Industrial Management, Springer, pp 511-522

Paul, S. K., Azeem, A., Sarker, R., \& Essam, D. (2014). Development of a production inventory model with uncertainty and reliability considerations. Optimization and Engineering, 15(3), 697-720.

Pekkanen, P., Niemi, P., Puolakka, T., Pirttilä, T., \& Huiskonen, J. (2020). Building integration skills in supply chain and operations management study programs. International Journal of Production Economics, 225, 107593.

Ponte, B., Puche, J., Rosillo, R., \& de la Fuente, D. (2020). The effects of quantity discounts on supply chain performance: Looking through the bullwhip lens. Transportation Research Part E: Logistics and Transportation Review, 143, 102094.

Poveda-Bautista, R., Baptista, D. C., \& García-Melón, M. (2012). Setting competitiveness indicators using bsc and anp. International Journal of Production Research, 50(17), 4738-4752.

Pérez-Vergara, I., Cifuentes-Laguna, A. M., Vásquez-García, C., \& Marcela-Ocampo, D. (2013). Un modelo de gestión de inventarios para una empresa de productos alimenticios. Ingeniería Industrial, 34(2), 227-236.

Pérez Vergara, I. G., Arias Sánchez, J. A., \& Poveda-Bautista, R., Diego-Mas J. A. (2020) Improving distributed decision making in inventory management: A combined abc-ahp approach supported by teamwork. Complexity, 3-5, 1-13.

Ray, P., \& Jenamani, M. (2016). Sourcing decision under disruption risk with supply and demand uncertainty: A newsvendor approach. Annals of Operations Research, 237(1-2), 237-262.

Santiago, S. B., de Oliveira, F. L., Rodriguez, C. M. T., \& Vergara, I. G. P. (2019). A method to measure logistic interoperability using structural equation modelling. In: Proceedings of the International Conference on Industrial Engineering and Operations Management, pp 2269-2280

Scala, N. M., Rajgopal, J., \& Needy, K. L. (2013). Managing nuclear spare parts inventories: A data driven methodology. IEEE Transactions on Engineering Management, 61(1), 28-37.

Seow, P. S., Pan, G., \& Koh, G. (2019). Examining an experiential learning approach to prepare students for the volatile, uncertain, complex and ambiguous (vuca) work environment. The International Journal of Management Education, 17(1), 62-76.

Singh, R. K., \& Acharya, P. (2013). Supply chain flexibility: A frame work of research dimensions. Global Journal of Flexible Systems Management, 14(3), 157-166.
Singh, R. K., Modgil, S., \& Acharya, P. (2019). Assessment of supply chain flexibility using system dynamics modeling. Global Journal of Flexible Systems Management, 20(1), 39-63.

Shukla, S. K., Sushil, \& Sharma, M. K. (2019). Managerial paradox toward flexibility: Emergent views using thematic analysis of literature. Global Journal of Flexible Systems Management, 20(4), 349-370.

Verma, S., \& Gustafsson, A. (2020). Investigating the emerging covid-19 research trends in the field of business and management: A bibliometric analysis approach. Journal of Business Research, 118, 253-261.

Vidal Holguín, C. J. (2010). Fundamentos de control y gestión de inventarios. Califoria, Colombia: Programa Editorial UNIVALLE.

Vitasek, K., \& Ledyard, M. (2013). Vested outsourcing: five rules that will transform outsourcing. New York: Springer.

Vitasek, K., Ledyard, M., \& Manrodt, K. (2013). Getting to we: A new negotiating model. Vested Outsourcing (pp. 177-184). New York, The United States: Springer.

Weenk, E. (2019). Mastering the Supply Chain: Principles, Practice and Real-life Applications. Great Britain: Kogan Page Publishers.

WHO. (2010). https://www.who.int/csr/disease/swineflu/frequently_ asked_questions/pandemic/es/

WHO. (2020). Covid-19 essential supplies forecasting tool overview of the structure, methodology, and assumptions used: Interim guidance, 25 August 2020

Winkelhaus, S., \& Grosse, E. H. (2020). Logistics 4.0: a systematic review towards a new logistics system. International Journal of Production Research, 58(1), 18-43.

Zuluaga, C. A. C., Gallego, M. C. V., \& Urrego, J. A. C. (2011). Clasificación abc multicriterio: tipos de criterios y efectos en la asignación de pesos. Iteckne, 8(2), 163-170.

Publisher's Note Springer Nature remains neutral with regard to jurisdictional claims in published maps and institutional affiliations.

\section{Key Questions}

1. How to stabilize a supply chain in times of turbulence or global unexpected disruption?

2. How to break the silos mentality present in companies and Supply Chain?

3. How suitable and flexible are inventory models based on optimization for mitigating disruption in supply chains during a global pandemic or similar risk?

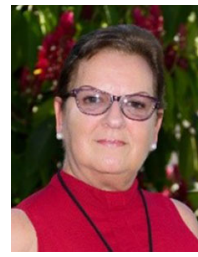

Ileana Gloria Pérez Vergara is an Industrial Engineer, Master in Optimization Techniques and Decision Support and Doctor in Technical Sciences, from the Technological University of Havana and University Specialist in Six Sigma Management Methodology, Polytechnic University of Valencia, Spain. She is the author of numerous books and scientific articles in highimpact journals. She serves as a full-time professor at the Faculty of Engineering at the University of San Buenaventura. 


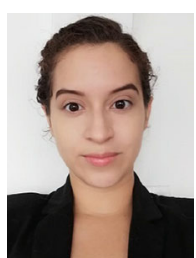

María Camila López Gómez is currently head of Supply Chain Management at Yumbo Company, Valle del Cauca. She is an Industrial Engineer from University of San Buenaventura, located in Cali, Colombia. Her experience includes the development of inventory control models, the improvement of service level and the reduction of inventory costs.

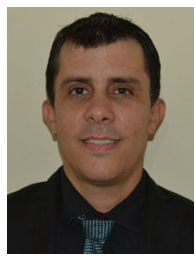

Igor Lopes Martínez is an Industrial Engineer from the Technological University of Havana. He received a $\mathrm{PhD}$ in Technical Sciences focusing in Logistics and Supply Chain (2013) at the same University, with the co-tutoring of TH-Wildau, Germany; is active in Teaching, Research and Business Consulting. He has accumulated more than fifteen years of experience as a Professor at Universities in Cuba and Latin America, and ten years of experience in joint work with Universities Worldwide, specially in Germany. Full Professor at Technological University of Havana, conducts research in the areas of Supply Chain, Industry 4.0, Inventory Management, Auto-ID and Circular Supply Chains; and teaches undergraduate and graduate subjects in the same areas.

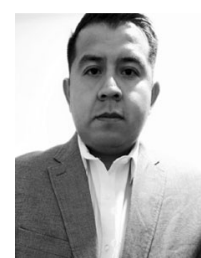

Jesús Vargas Hernández is currently a full-time professor at the Industrial Engineering Department at the Autonomous University of Mexico State (UAEMex). He obtained his PhD in Materials in a cotutelle doctorate between the National Polytechnic Institute (Mexico) and the University of Le Mans (France) and has participated in several conferences. His research interest includes nanomaterials, semiconductors, metal alloys, photocatalysis, thermal treatments. He is currently the coordinator of a Supply Chain Management and Logistics Program. 